\begin{abstract}
:
This study analyzes the time-frequency relationship between oil price and exchange rate for Pakistan by using measures of continuous wavelet such as wavelet power, cross-wavelet power, and cross-wavelet coherency. The results of cross-wavelet analysis indicate that covariance between oil price and exchange rate are unable to give clear-cut results but both variables have been in phase and out phase (i.e. they are anti-cyclical and cyclical in nature) in some or other durations. However, results of squared wavelet coherence disclose that both variables are out of phase and real exchange rate was leading during the entire period studied, corresponding to the 10 15 months scale. These results are the unique contribution of the present study, which would have not been drawn if one would have utilized any other time series or frequency domain based approach. This finding provides evidence of anti-cyclical relationship between oil price and real effective exchange rate. However; in most of the period studied, real exchange rate was leading and passing anti-cycle effects on oil price shocks which is the major contribution of the study.
\end{abstract}

Keywords: Oil prices, exchange rate, Pakistan 


\section{Analyzing Time-Frequency Relationship between Oil Price and Exchange Rate in Pakistan through Wavelets}

\section{Introduction}

Oil prices affect real effective exchange rate via supply-side and demand side mechanisms. Explaining supply-side effects, crude oil is basic input used in production process. So, rise in oil prices is linked with an increase in the cost of production of non-tradable products and in resulting, this rise in prices of non-tradable goods appreciates real effective exchange rate. Indirectly, an increase in disposable income also leads an appreciation in real effective exchange rate. Consumer spending power is highly affected by a rise in oil prices. This reduces the demand for non-tradable products and in turn, prices of non-tradable goods have fallen which deprecates the real effective exchange rate. Hamilton, [1] started a debated on the relationship between oil prices and macroeconomic variables. For example; Hamilton, [1] explored the association between oil prices and US business cycle. Various researchers contributed in existing literature by investigating relationship between oil prices and stock market returns (Sadorsky, [2, 3,4]; Papapetrou, [5]); between economic growth and stock market development (Shahbaz et al. [6]) and relationship between exchange rate and oil prices is also investigated by Bénassy-Quéré et al. [7]; Chen and Chen, [8]; Huang and Guo, [9]; Olomola and Adejumo, [10]; Kutan and Wyzan, [11] and many more.

This paper deals with empirical investigation between oil prices and real effective exchange rate in case of Pakistan over the period of $1986 \mathrm{M}_{2}-2009 \mathrm{M}_{3}$. Few studies are also available examining Pakistan's macroeconomic fundamentals. For example, nominal and real effective exchange rates (Shahbaz, [12]; saving-investment and capital outflows (Shahbaz et al. [13]); capital inflows and economic growth (Shahbaz and Rahman, [14]); real effective exchange 
rate and trade balance (Shahbaz et al. [15]); terms of trade and trade balance i.e. J-curve (Shahbaz et al. [16]); devaluation and economic growth (Shahbaz et al. [17]); financial development, foreign direct investment and economic growth (Shahbaz and Rahman, [18]); trade openness and economic growth (Shahbaz, [19]) ${ }^{1}$ and, money supply and interest rate (Khattak et al. [21]). What is in remainder to investigate the relationship between oil prices and real effective exchange rate in case of Pakistan. Pakistan is lower middle income country heavily depends on oil imports to boost economic activity and hence economic growth. The empirical investigation of impact of oil prices on exchange rate is very important for policy making point of view.

Our study makes important contributing in the existing literature by three ways. In the first place, the much debated question of whether or not a causal relationship exists between the oil price and exchange rate, calling upon the notion of causality based on the pioneering work of Granger, [22]. Secondly, within this causality debate, the relevance of frequency domain concepts is introduced as Granger and Lin, [23] documented that the extent and direction of causality can differ between frequency bands. Thirdly, we introduced time series concept with frequency domain, hence, we analyzed time-frequency relationship as in the frequency domain framework time information is lost. So, in our contribution, we used continuous wavelets tools such as the wavelet power spectrum, wavelet coherency, and wavelet phase difference to analyze the impact of oil price changes on exchange rate and vice-versa. The wavelet power spectrum illustrates the evolution of the variance of a time-series at the different frequencies; the wavelet coherency demonstrates the correlation coefficient in the time-frequency space; and the information on the delay between the oscillations of two time-series i.e. lead-lag relationship s provided by phase difference. Our major contribution lies in providing evidence of anti-cyclical relationship between oil price and real effective exchange rate however, in most of the period 
studied we found that real exchange rate was leading and passing anti-cycle effects on oil price shocks.

The rest of paper is organized as following: section-II provides review of literature; section-III explains methodology and data collection. Results are interpreted in section-IV and conclusions and future research are drawn in section- $\mathrm{V}$.

\section{Literature Review}

The relationship between oil prices and exchange rate nexus has been discussed by Krugman, [24]; Golub, [25]; Corden, [26]; Rogoff, [27] and many more. These studies argument that in oil exporting countries, a rise in oil prices appreciates local currency against US dollar and US dollar exchange rate depreciates due to rise in oil prices in oil importing countries. Moreover, Amano and van Norden, [28] examined the cointegration and causality relationship between oil prices and exchange rate in case of Germany, Japan and the United States. Their results showed cointegration relationship between the variables and oil price change leads to appreciate the US dollar in long span of time. The causality analysis also supported their view by providing unidirectional causality running from oil prices to exchange rate in Germany, Japan and US. In case of OECD countries, Chauhuri and Daniel, [29] discussed the issue of oil prices and exchange rate by applying Engle-Granger, [30] cointegration approach and reported that both variables cointegrated in 13 out of 16 countries. Furthermore, exchange rate is Granger caused by oil price changes.

Rautava, [31, 32] examined the role of oil prices and exchange rate changes in Russian economy. The results showed cointegration between the variables and oil prices inversely affect output and Russian exchange rate ${ }^{2}$. Bénassy-Quéré et al. [7] unveiled the relationship between 
oil prices and real effective exchange rate in case of China. They reported that both variables are cointegrated for long run relationship and the VECM Granger causality analysis showed positive causal relationship runs from oil prices to exchange rate in short run while in long run causality is negative running from oil prices to exchange rate. Similarly, for Dominican Republic, Dawson, [34] investigated the impact of oil prices on exchange rate using VAR approach. The findings indicated that oil prices rise is inversely linked with exchange rate. Dawson documented that a 2.9 percent depreciation in real exchange rate is Granger caused by 1 percent increase in oil price and this phenomenon is more relevant for short run. Chen and Chen, [8] borrowed model developed by Chauhuri and Daniel, [29] to analyse the relationship between oil prices and exchange rate using data of G-7 countries. Their results indicated that both variables are cointegrated for long run using panel cointegration approach.

Huang and Guo, [9] collected data on oil prices and exchange rate in case of China to examine the nature of relationship between them. By applying SVAR model, they found that real oil price shocks appreciate the US dollar minimally in long run due to lesser dependence on oil imports. Issa et al. [35] revisited the association between energy prices and Canadian dollar by applying the model advanced by Amano and van Norden, $[28]^{3}$. Their results reported that energy prices depreciate Canadian dollar. Coudert et al. [37] reconsidered the relationship between oil prices and exchange rate in case US. They found cointegration between the variables and oil price Granger cause exchange rate ${ }^{4}$. Rickne, [39] found that co-movements between oil prices and US dollar exchange rate depends on political and legal institutions. Currencies are less effective by oil price changes in countries where bureaucracies and legal systems are strong. In case of US, Huang and Tseng, [40] investigated the relationship between crude oil prices and US dollar exchange rate using auxiliary regression. They found cointegration between both variables 
while causality results indicated that feedback effect is found between oil prices and exchange rate $^{5}$. Leili, [42] unveiled the relationship between real oil prices and real effective exchange rate using the data of OPEC. The finding indicates that dominant source of movements in exchange rate is due to real oil prices shocks in long run. In case of US, Lizardo and Mollick, [43] found long run relationship between the series. They reported that rise in oil prices depreciate the US dollar against net exporter countries such as Canada, Mexico, and Russia and vise versa for oil importer countries ${ }^{6}$.

In case of India; Ghosh, [45] probed the relationship between crude oil prices and exchange rate using generalized autoregressive conditional heteroskedasticity $(\mathrm{GARCH})$ and exponential GARCH (EGARCH) models. Ghosh reported unidirectional causality running from oil prices to exchange rate (depreciating Indian currency against US dollar) and changes in oil prices affect exchange rate permanently. In case UAE; Al-mulali and Sab, [46] examined impact of oil prices shocks on exchange rate of UAE Dirham in fixed exchange regime. They found that oil prices shocks do not seem to lead exchange rate but stimulated gross domestic product and liquidity which in resulting caused domestic prices to rise and hence inflation. Treviño, [47] disclosed the relationship between oil price and exchange rate in oil-rich countries of the Central African Economic and Monetary Community (CEMAC) by applying procedure developed by Ismail $[48]^{7}$. The results showed that oil price appreciates real exchange rate which confirms the presence of Dutch disease that restrict these economies to attain high economic growth in long run. In addition; Kanturk, [49] examined the effect of oil prices on exchange rate volatility in Turkey and concluded that rise in oil prices has significant impact on exchange rate volatility but impact is restrained during financial crisis. 
Wu et al. [50] examined co-movements between oil prices and exchange rate by applying copula-based GARCH model in case of US economy. They reported that copula GARCH model label the volatility and dependence structure of oil price and US dollar exchange rate returns, CAMP model reveals that feedback trading activities are found significant in oil market but inference is not drawn in USDX market, GARCH model indicates that short run volatility is persistence and less than long run volatility for oil prices features but it is significant for USDX features. Similarly; Reboredo, [51] conducted a study to model the co-movements between oil prices and exchange rate using correlations and copulas approaches ${ }^{8}$. The results indicated that oil price rise is weakly linked with US dollar depreciation and vice versa, the strength of comovements is found different across currencies. For example, intensity is high for oil exporting countries such as Canada, Norway and Mexico and low intensity is found in oil importing courtiers, especially in Japan where there is no interdependence between oil prices and exchange rate movements. The interdependence between the variables is increased after financial crisis, once, the coefficient of linear correlation raises to maximum value of 0.45. Basher et al. [52] unveiled the relationship between oil price and exchange rate in emerging markets ${ }^{9}$. Their results reported that a positive shock to oil prices Granger cause US dollar exchange rate to decline in short run in all emerging economies. In case of Malaysia; Hussein et al. [53] investigated the causality between oil price and US dollar exchange rate. They found cointegration between the variables and unidirectional causal relationship is found running from oil price to US dollar exchange rate. In US economy; Benhmad, [54] disclosed unidirectional causality running from real oil prices to real effective exchange rate applying linear and non-linear Granger causality approaches. 
Beckmann and Czudaj, [55] examined the dynamics between oil prices and US dollar exchange rate and reported bidirectional causality between the both variables. Coleman et al. [56] disclosed the nexus between oil price and exchange rate in African countries ${ }^{10}$. They found cointegration between the variables and oil price changes paly vital role in determining real exchange rate but this effect is different across the countries may be due to difference in economic structure. Turhan et al. [57] uncovered the role of oil price in determining the exchange rate in emerging economies ${ }^{11}$. Their results indicated that oil price rise is leading indicator to appreciate the currencies of these market against US dollar. Moreover, analysis of generalized impulse response function reveals that impact of oil price on exchange rate is significant after 2008 financial crisis. Adeniyi et al. [58] analyzed the relationship between oil prices and exchange rate using GARCH and exponential GARCH (EGARCH) in case of Nigeria. They found that oil price rise appreciates Nigerian currency against US dollar and same inference was drawn by Olomola and Adejumo, [10] and latter on by Oriavwote and Eriemo, [59] ${ }^{12}$. Apart from that Englama et al. [60] reported that a 1 per cent increase in permanent shock in oil prices adds in 0.54 per cent shock in exchange rate unpredictability in long run while foreign exchange demand leads exchange rate volatility dominate. Latter on, Hassan and Zahid, [61] and, Ozsoz and Akinkunmi, [62] also found positive impact of oil prices on Nigerian real effective exchange rate. Recently, Tiwari et al. [63] applied the wavelet approach to probe the relationship between oil prices and real effective exchange rate using the data of Indian economy. They found neutral effect between both variables at the lower time scale but at higher time scales, real effective exchange rate Granger cause oil prices. 


\section{Data and methodology}

For empirical purpose, we have collected monthly frequency data on oil prices and real effective exchange rate over the period of 1986-2009. The data span is large and sufficient for reliable and consistent results. Exchange rate is proxied by real effective exchange rate and collected from international financial statistics (CD-ROM, 2010). The crude oil price variable is expressed in real terms, i.e. deflated by U.S. consumer price index following Faria et al. [64]. The data on crude oil prices are the spot prices and collected from Pakistan Energy Year Book (Government of Pakistan).

\section{III.I Motivation and Introduction to Methodology}

Existing economic literature provides various studies applying various approaches to investigate the relationship between oil prices and exchange rate changes. The researchers have not paid their attention to apply the time domain and frequency domain approaches in examining the relationship between both series. There may be a relationship between the series at different frequencies such as oil price may act like a supply shock at lower and medium frequencies (Naccache, [41]) and in resulting it affects real effective exchange rate. In short span of time i.e. at the higher frequencies, real effective exchange rate affects oil prices following demand-effect. It is a general practice in existing economic literature to unveil relationship between the series at different frequencies using Fourier analysis. The demerits of Fourier analysis are also discussed in the existing literature. For example, Fourier transform does not seem to capture the time information which makes difficult to get information about short-lived relationship or structural break stemming in the series. These structural breaks are very important for policy making point of view. Furthermore, results provided by Fourier transform are less reliable. This approach 
works well when series do not have unit root problem at level but macroeconomic variables are found non-stationary at level usually. This implies that error term of non-stationary series is not normally distributed and provides biased results. This issue has been resolved by Gabor, [65] who advanced a specific transformation of Fourier transform which is also called a short time Fourier transformation. The short time Fourier transformation breaks into smaller sub-samples to apply Fourier approach on each sub-sample. Although, this approach is also criticized on the basis of its efficiency as it takes equal frequency resolution across all dissimilar frequencies (see Raihan et al. [66] for detail). This issue has provided a space for wavelet transform approach. This approach is advantageous over Fourier transformation from various aspects. For example, wavelet transform approach performs "natural local analysis of a time-series in the sense that the length of wavelets varies endogenously: it stretches into a long wavelet function to measure the low-frequency movements; and it compresses into a short wavelet function to measure the highfrequency movements" Aguiar-Conraria and Soares [67]. Wavelet transform works within the spectral framework for analysis of the time series and it is a function of time. This implies that wavelet approach illustrates the changes stemming in the series with the passage of time and at various periodic components or frequency bands.

It is noted that discrete wavelet transformation is not applied extensively in economics and finance. There is a question, up to what extent we should decompose while employing discrete wavelet approach. Moreover, wavelet discrete analysis is not much helpful for economists and policy makers in formulating a comprehensive economic policy. This continues transformation of discrete wavelet analysis may provide more reliable and understandable results at each scale following the variations in the time series data. For example, looking at Figure-1 one can immediately conclude the evolution of the variance of the return series of oil price and 
exchange rate at the several time scales along the 20 year observation and extract the conclusions with just a single diagram. Aguiar-Conraria et al. [68] pointed out the wavelets due to its two interesting features. For example, Aguiar-Conraria et al. ([68], p. 2865) pointed out that "first, in most economic applications the (discrete) wavelet transform has mainly been used as a low and high pass filter, it being hard to convince an economist that the same could not be learned from the data using the more traditional, in economics, band pass-filtering methods. The second reason is related to the difficulty of analyzing simultaneously two (or more) time series. In economics, these techniques have either been applied to analyze individual time series or used to individually analyze several time series (one each time), whose decompositions are then studied using traditional time-domain methods, such as correlation analysis or Granger causality”.

The above issued have been solved by Hudgins et al. [69] and Torrence and Compo, [70] developing the cross-wavelet power, the cross-wavelet coherency, and the phase difference to accommodate the analysis of time frequency dependencies between two time series. Using crosswavelet tools, we can analyze relationship between two series at different frequencies. The single wavelet power spectrum is helpful to recognize the development of variations in the series at different frequencies as well as with periods of large variance associated with periods of large power at the different scales. Furthermore, cross-wavelet power also shows the curbed covariance between the variables. The wavelet coherency can be interpreted as correlation coefficient in the time-frequency space. This phase term indicates the position of pseudo-cycle of the time which is function of occurrence. Similarly, the phase difference gives us information "on the delay, or synchronization, between oscillations of the two time series" (Aguiar-Conraria et al. [68], p. 2867). 


\section{III.II The Continuous Wavelet Transform (CWT) ${ }^{13}$}

The continuous wavelet transform approach is contained to both frequency and time having zero mean. The major advantage of continuous wavelet transform is that it can be characterized by localizing continuous wavelet transform in time $(\Delta t)$ and frequency $(\Delta \omega)$ or in both. It is exposed by Heisenberg uncertainty principle that tradeoff exists between localization in time and frequency. We have to properly define $\Delta t$ and $\Delta \omega$ because there is a minimum limit for the uncertainty product (yellow I have edited) $\Delta t \cdot \Delta \omega$. The Morlet wavelet, most often used in research, is defined as following:

$\psi_{0}(\eta)=\pi^{-1 / 4} e^{i \omega_{0} \eta} e^{-\frac{1}{2} \eta^{2}}$.

where dimensionless frequency and time is indicated by $\omega_{0}$ and $\eta$ respectively. The Morlet wavelet (with $\omega_{0}=6$ ) approach is an appropriate option for feature extraction because it provides a good balance between time and frequency localization. This approach is applied to the wavelet as band pass filter to the time series. The wavelet is stretched in time by varying its scale (s), so that $\eta=s \cdot t$ and normalizing it to have unit energy. For the Morlet wavelet (with $\omega_{0}=6$ ) the Fourier period $\left(\lambda_{w t}\right)$ is almost equal to the scale $\left(\lambda_{w t}=1.03 \mathrm{~s}\right)$. The CWT of a time series $\left(x_{n}, n=1, \ldots, N\right)$ with uniform time steps $\delta t$, is defined as the convolution of $x_{n}$ with the scaled and normalized wavelet. We write as:

$$
W_{n}^{X}(s)=\sqrt{\frac{\delta t}{s}} \sum_{n^{\prime}=1}^{N} x_{n^{\prime}} \psi_{0}\left[\left(n^{\prime}-n\right) \frac{\delta t}{s}\right]
$$


The power of wavelet is defined as $\left|W_{n}^{X}(s)\right|^{2}$ and local phase is simple interpretation of the complex argument of $W_{n}^{X}(s)$. The CWT has edge artifacts because the wavelet is not completely localized in time. The introduction of Cone of Influence (COI) is useful to a point where edge effects are accepted. We observe the COI as the area in which the wavelet power caused by a discontinuity at the edge has dropped to $e^{-2}$ of the value at the edge. The null hypothesis is used to asses the statistical significance of wavelet power while background power spectrum $\left(P_{k}\right)$ is used to generate stationary process ${ }^{14}$. Torrence and Compo, [70] estimated the white noise as well ass red noise wavelet power spectra. Both estimates have been derived from corresponding distribution following wavelet power spectrum at every point of time $n$ as well as scale $s$. The corresponding distribution is as following:

$$
D\left(\frac{\left|W_{n}^{X}(s)\right|^{2}}{\sigma_{X}^{2}}<p\right)=\frac{1}{2} P_{k} \chi_{v}^{2}(p),
$$

where $v$ is equal to 1 for real and 2 for complex wavelets.

\section{III.III The Cross Wavelet Transform (CWT)}

$W^{X Y}=W^{X} W^{Y^{*}}$ is definition of the cross wavelet transform (CWT) of the two variables such as $x_{n}$ and $y_{n}$. The $W^{X}$ and $W^{Y}$ are transformation of the wavelet transforms for $x$ and $y$ time series respectively and $*$ is complex conjugation. $\left|W^{X Y}\right|$ is the definition of cross wavelet 
power. The i complex argument such as $W^{x y}$ interprets the local relative phase for $x_{n}$ and $y_{n}$ time series using time frequency space. Torrence and Compo, [70] generated the distribution of the cross wavelet power for two time series with background power spectra $P_{k}^{X}$ and $P_{k}^{Y}$ which is given as following:

$$
D\left(\frac{\left|W_{n}^{X}(s) W_{n}^{Y^{*}}(s)\right|}{\sigma_{X} \sigma_{Y}}<p\right)=\frac{Z_{v}(p)}{v} \sqrt{P_{k}^{X} P_{k}^{Y}}
$$

where $Z_{v}(p)$ is level of confidence linked with the probability $p$ for a pdf which is defined by $\chi^{2}$ distributions.

\section{III.IV Wavelet Coherency (WTC)}

Following Fourier spectral approach, we can define Wavelet Coherency (WTC). The Wavelet Coherency is a ratio of the cross-spectrum to the product of the spectrum of each series. This indicates local correlation between two time series within time and frequency. So, the Wavelet Coherency presents a high resemblance if coherence is near to 1 otherwise no relationship is found between the time series. The Wavelet power spectrum shows the variance of the series. The larger variance in Wavelet power spectrum shows large power. The covariance between the time series is represented by the Cross Wavelet power following all frequencies or scales. Aguiar-Conraria et al. ([68], p. 2872) defines Wavelet Coherency as "the ratio of the cross-spectrum to the product of the spectrum of each series, and can be thought of as the local (both in time and frequency) correlation between two time-series". 
So, Torrence and Webster, [71] define the Wavelet Coherence of two time series as following:

$$
R_{n}^{2}(s)=\frac{\left|S\left(s^{-1} W_{n}^{X Y}(s)\right)\right|^{2}}{S\left(s^{-1}\left|W_{n}^{X}(s)\right|^{2}\right) \cdot S\left(s^{-1}\left|W_{n}^{Y}(s)\right|^{2}\right)},
$$

where, smoothing operator is shown by $S$. It is a traditional correlation coefficient definition which is helpful in thinking of the Wavelet Coherence as a localized correlation coefficient following time frequency space. We rewrite the equation-5 once smoothing operator is equalant to 1 and smoothing operator $S$ as a convolution in time and scale:

$$
S(W)=S_{\text {scale }}\left(S_{\text {time }}\left(W_{n}(s)\right)\right)
$$

where $S_{\text {scale }}$ denotes smoothing along the wavelet scale axis and $S_{\text {time }}$ indicates smoothing in time. The time of convolution is determined using Gaussian and scale convolution is done by regular window (Torrence and Compo, [70]). The functional form of smoothing power following Morlet wavelet is articulated as:

$$
\begin{aligned}
& \left.S_{\text {time }}(W)\right|_{s}=\left.\left(W_{n}(s) * c_{1}^{-t^{2} / 2 s^{2}}\right)\right|_{s} \\
& \left.S_{\text {scale }}(W)\right|_{n}=\left(\left.W_{n}(s) * c_{2} \Pi(0.6 s)\right|_{n}\right.
\end{aligned}
$$


where, normalized constants are $c_{1}$ and $c_{2}$ while $\Pi$ denotes is the rectangle function. The scale de-correlation length for Morlet wavelet is empirical determined by 0.6. Practically, we determine co-evolutions directly but normalized coefficients indirectly. The Monte Carlo simulation approach is used to asses the theoretical distributors of wavelet coherency. To test the wavelet coherency, we follow Aguiar-Conraria and Soares, [67] rather than Wavelet Cross Spectrum. Aguiar-Conraria and Soares, ([67], p. 649) gives two arguments for this: “(1) the wavelet coherency has the advantage of being normalized by the power spectrum of the two time-series, and (2) that the wavelets cross spectrum can show strong peaks even for the realization of independent processes suggesting the possibility of spurious significance tests".

\section{III.V Cross Wavelet Phase Angle}

The phase difference between the components is estimated by using mean and confidence interval of the phase difference of two time series. The phase relation is measured by the circular mean of the phase, which is if, over the regions higher than 5 per cent level of significance and outside the COI to measures the phase relation. The useful and general method to investigate mean phase using a set of angles $\left(a_{i}, i=1, \ldots, n\right)$ can be defied as following:

$a_{m}=\arg (X, Y)$ with $X=\sum_{i=1}^{n} \cos \left(a_{i}\right)$ and $Y=\sum_{i=1}^{n} \sin \left(a_{i}\right)$

The independence of phase angles is helpful in calculating reliable confidence interval of the mean angle. The number of angles used in the calculation can be set arbitrarily high simply 
by increasing the scale resolution. Nevertheless, the scatter of angles around the mean is very interesting. The spherical standard deviation can be defined as following:

$$
s=\sqrt{-2 \ln (R / n)},
$$

where $R=\sqrt{\left(X^{2}+Y^{2}\right)}$. The spherical standard deviation is similar to linear standard deviation and its value ranges from zero to infinity. The close distribution of angles around the mean angle does not make difference in results and results are similar with linear standard deviation. In some cases there might be reasons for calculating the mean phase angle for each scale, and then the phase angle can be quantified as a number of years. The Monte Carlo methods are used to find statistical level of significance of the wavelet coherence. We generate a large ensemble of surrogate data set pairs with the same $\operatorname{AR}(1)$ coefficients as the input datasets. We investigate the wavelet coherence for each pair. The level of significance for every scale is estimated using the values outside the COI. The number of lags in phase for wavelets is defined as following:

$\phi_{x, y}=\tan ^{-1} \frac{I\left\{W_{n}^{x y}\right\}}{R\left\{W_{n}^{x y}\right\}}, \phi_{x, y} \in[-\pi, \pi]$

The real and imaginary parts are indicated by $I$ and $R$ respectively, of the smooth power spectrum. The phase relationship between the two times series is characterized using path difference which is considered useful. The time series moves together with specified frequency if value of phase difference ranges to zero. The series move in phase if $\phi_{x, y} \in[0, \pi / 2]$ when series $\mathrm{x}$ 
is lead by y series. On contrary, if $\phi_{x, y} \in[-\pi / 2,0]$ then $\mathrm{x}$ is leading. We have an anti-phase relation (analogous to negative covariance) if we have a phase difference of $\pi$ (or $-\pi$ ) meaning $\phi_{x, y} \in[-\pi / 2, \pi] \cup[-\pi, \pi / 2]$. If $\phi_{x, y} \in[\pi / 2, \pi]$ then $\mathrm{x}$ is leading, and the time series $\mathrm{y}$ is leading if $\phi_{x, y} \in[-\pi,-\pi / 2]$.

\section{INSERT FIGURE 1 ABOUT HERE}

\section{Results and their Discussions}

We have converted both series into logarithm to obtain unbiased and efficient results. The graphs of both variables are shorn in Figure-1. The results of descriptive statistics and correlation matrices are reported in Table-1 containing log levels as well as in returns. The sample mean of $\log$ of real effective exchange rate and for returns data of oil prices is positive. The sample mean of oil prices is negative and higher as compared to returns data for real effective exchange rate. The degree skewness shows that real effective exchange rate and oil prices in level are positively skewed and negatively skewed in return data set for both variables. The data is more skewed of level oil prices and returns data set for real effective exchange rate. The measure of Kurtosis indicates that oil prices in level as well as in return data set has more leptokurtic distribution compared to normal distribution. The correlation coefficient reports that real effective exchange rate and oil prices are negatively correlated in level form and same inference is drawn for return data set of both series.

INSERT TABLE 1 ABOUT HERE 
To test the stationery properties of running series, we applied ADF (Dickey and Fuller, [72]) and PP (Philips and Perron, [73]). The results of both tests are shown in Table-2. The Table-2 indicates that both variables show unit root behavior at level and found stationery at $1^{\text {st }}$ difference with intercept and trend. The findings of ADF and PP unit root tests may be biased due not having information about structural breaks stemming in the series. To solve this issue, we have applied de-trended Zivot and Andrews, [74] structural break unit test to examine the integrating orders of the variables in the presence of structural breaks. The results are reported in lower segment of Table-2. We found that the series are found non-stationery at level showing structural breaks in $2002 \mathrm{M}_{1}$ and $1998 \mathrm{M}_{12}$ in real effective exchange rate and oil prices respectively ${ }^{15}$. Real effective exchange rate and oil prices are found to be integrated at I(1). This implies that variables have same level of stationarity i.e. I(1).

\section{INSERT TABLE 2 ABOUT HERE}

The next step is to apply the ARDL bounds testing approach in the presence of structural breaks due to major economic events affecting these series. The appropriate leg order is prerequisite to apply bounds testing to examine long run relationship between the variables. In doing, we chose Akaike information criteria (AIC) to select lag order of the variables. It is suggested by (Lütkepohl, [75]) that we should apply AIC to choose leg length because it provides better results as compared to sequential modified LR test statistic (LR), final prediction error (FPE); Schwarz information criterion (SIC) and Hannan-Quinn information criterion (HQ). The lag order 5 is chosen following the minimum value of AIC and results of shown in second column of Table- 3 . 
The next step is to compute F-statistic following the ARDL bounds testing approach to cointegration to examine long run relationship between real effective exchange rate and oil prices. We use critical bounds generated by Pesaran et al. [76] for large sample (279 observations). The empirical evidence shows that our computed F-statistic exceeds upper critical bound (UCB) i.e. $7.269>4.68$ once real effective exchange rate is used as forcing variable. This implies that there is one cointegrating found confirming long run relationship exists between real effective exchange rate and oil prices in case of Pakistan over the period of $1986 \mathrm{M}_{1}-2009 \mathrm{M}_{3}$.

\section{INSERT TABLE 3 ABOUT HERE}

The next step is to analyze continuous wavelet power spectrum for both variables. It is evident from Figure-2 that there are some common islands. In particular, the common features in the wavelet power of the two time series are evident in 1990s and 2006 and then 2007. The important point here is less evidence of Common Island for common frequencies and for same

year. However, the similarity between the portrayed patterns in these periods is not very much clear and it is therefore hard to tell if it is merely a coincidence. The cross wavelet transform helps in this regard. We further, analyzed the nature of data through cross wavelet and presented results in Figure-3.

INSERT FIGURE 2 ABOUT HERE

INSERT FIGURE 3 ABOUT HERE 
It is very interesting to see that in Figure-3, the direction of arrows at different periods (i.e. frequency bands) over the time period studied is not same. We observe that the variables during 1990s are out of phase (if we focus on significance region) and up to 1998 they are out of phase, if we consider high-power region. However, after 1998 we observe that the variables are in phase (if we consider high power region) and significant region is not observed after 1998. The most critical point is that direction of the arrows i.e. whether they are right-up or left-up (or right-down or left-down) is not very clear. So, it is very difficult to tell which variable is leading and which one is lagging in different frequency bands and periods. In other words, outside the areas with significant power, the phase relationship and also lead-lag relationship is also not very clear. Even if, now, we do not have very clear results but this type of results one analyst would have not got if he/she would have utilized either time series or spectral or frequency analysis based methods. Overall we, therefore, speculate that there is a stronger link between returns series of oil price and exchange rate than that implied by the cross wavelet power.

Further, it is worthy to mention that wavelet cross-spectrum (i.e. cross wavelet) describes the common power of two processes without normalization to the single wavelet power spectrum. This can produce misleading results, because one essentially multiplies the continuous wavelet transform of two time series. For example, if one of the spectra is locally and the other exhibits strong peaks, peaks in the cross spectrum can be produced that may have nothing to do with any relation of the two series. This leads us to conclude that wavelet cross spectrum is not suitable to test the significance of relationship between two time series. Therefore, in our conclusion we relied on the wavelet coherency (as it is able to detect a significant interrelation between two time series, to know more about refer to the section-III.II). However, one can still use wavelet cross-spectrum to estimate the phase spectrum. The wavelet coherency is used to 
identify both frequency bands and time intervals within which pairs of indices are co-varying. Finally, we presented results of cross-wavelet coherency in Figure-4.

\section{INSERT FIGURE 4 ABOUT HERE}

The squared WTC of return series of oil prices and real effective exchange rate are shown in Figure-4. If we compare results of WTC and XWT i.e. if we compare Figure-3 and Figure-4, we find very clear results of phase difference of lead-lag relationship between returns series of oil prices and real effective exchange rate in Figure-4. It is hard to tell the exact lead-lag relationship at very short scales of less than 5 months. However, arrows are left-up, in general, throughout the period corresponding to the 10 15 months scale. This finding indicates that the variables are out of phase throughout the period i.e. anti-cyclical effects are observed. Since arrows are pointing up this indicate that real exchange rate is leading. This is the most interesting part which comes now in existence (which did not appear in XWT analysis). Now with the application of WTC analysis we have very clear evidence on lead-lag relationship between return series of oil price and exchange rate. Further, we also come to know whether one variable influence or influenced by the other through anti-cyclical or cyclical shocks. Definitely these results would have not been drawn through the application of time series or fourier transformation analysis if one could have attempted.

\section{Conclusions and Future Research}

The study analyzed Granger-causality between oil prices and real effective exchange rate for Pakistan by using monthly data covering the period of $1986 \mathrm{M}_{2}-2009 \mathrm{M}_{3}$. We have 
decomposed the time-frequency relationship between oil price and real effective exchange rate by applying continuous wavelet approach. We have also used structural break unit test to examine the order of integration of both series and the ARDL bounds testing approach is applied to investigate long run relationship between oil price and real effective exchange rate in case of Pakistan.

Our results indicate that the variables are integrated at I(1) and are cointegrated for long run relationship. Furthermore, our results found from the continuous power spectrum that the common features in the wavelet power of the two time series are evident in 1990s and 2006 and latter on in 2007. The results of XWT, which indicate the covariance between oil price and exchange rate, are unable to give clear-cut results but indicate that both variables have been in phase and out phase (i.e. they are anti-cyclical and cyclical in nature) in some or other durations. However, our results of cross-wavelet coherency or squared wavelet coherence (WTC), which can be interpreted as correlation, reveal that both variables are out of phase and real exchange rate was leading during the entire period studied, corresponding to the $10 \sim 15$ months scale. These results are the unique contribution of the present study, which would have not been drawn if one would have utilized any other time series or frequency domain based approach. Our results indicate that causal and reverse causal relations between oil price and real effective exchange rate vary across scale in case of Pakistan. There are evidence of anti-cyclical relationship between oil price and real effective exchange rate however, in most of the period studied real exchange rate was leading and passing anti-cycle effects on oil price shocks.

Our results found that exchange rate is leading to pass anti-cyclical effects on oil prices shocks. To avoid these shocks, Pakistan government should control the exchange rate movement as it affects are moving backwards. This affects production process i.e. increases the cost of 
production where oil is used are input. The government should also focus in exploring news sources of energy as alternate of oil energy. This not only lowers the heavy dependence of Pakistan on oil imports but it would also be helpful in controlling the rapid movements in exchange rates due to sustainable deficit in trade as well ass in balance of payments. For future research, current study can be extended by analyzing the trivariate wavelet based approach which might include different interest rates and/or stock market return as a third variable as theoretically all the three variables are expected to be highly correlated with each other following Basher et al. [52]. The copula-based GARCH models can also be used to analyze co-movements between real effective exchange rate and oil prices following $\mathrm{Wu}$ et al. [50]. 


\section{Footnotes}

1. Nasreen, [20] also investigated the directional of causal relationship between exports and economic growth using data of Pakistan, India and Bangladesh.

2. Hamilton, [33] found that oil prices affects economic growth negatively.

3. Narayan et al. [36] also reported that oil prices lead exchange rate appreciation for Fiji Islands.

4. Aziz [38] reported no significant association between oil prices and real effective exchange rate.

5. Naccache, [41] examined co-movements between oil price and world macroeconomy proxies by Morgan Stanley Capital International (MSCI) and reported reverse causality theory.

6. Zhang et al. [44] noted that crude oil prices Granger cause US dollar to depreciate

7. Chad, Cameroon, Equatorial Guinea, Gabon, Republic of Congo, Benin, Burkina Faso, Cote d'Ivoire, Guinea Bissau, Mali, Niger, Senegal, Togo, Central African Republic

8. Germany, France, Italy, Netherlands, Belgium/Luxembourg, Ireland, Spain, Austria, Finland, Portugal, Greece, Slovenia, Cyprus, Slovakia, Malta, Australia, Canada, United Kingdom, Japan, Norway and Mexico.

9. Qatar, China, Kazakhstan, Algeria, Kuwait, Saudi Arabia, United Arab Emirates, Ecuador, Singapore, India, USA

10. Burkina Faso, Cameroon, Ivory Coast, Kenya, Madagascar, Mauritius, Morocco, Nigeria, Rwanda, Senegal, Seychelles, South Africa and Togo

11. Argentina, Brazil, Columbia, Indonesia, Mexico, Nigeria, Peru, Philippines, Poland, Russia, South Africa, South Korea and Turkey

12. Oriavwote and Eriemo [59] also reported unidirectional causality running from crude oil to real exchange rate. 
13. We are grateful to Grinsted and co-authors for making codes available at: http://www.pol.ac.uk/home/research/waveletcoherence/, which was utilized in the present study.

14. It is pointed out by Torrence and Compo, [70] that how the statistical significance of wavelet power can be assessed against the null hypothesis that the data generating process is given by an $A R(0)$ or $A R(1)$ stationary process with a certain background power spectrum $\left(P_{k}\right)$, for more general processes one has to rely on Monte-Carlo simulations.

15. The structural break in real effective exchange rate series is dealt with complete shift of Pakistan economy to floating exchange rate system. The structural break in oil prices deals with negative supply shock which raised real price of oil in the country. 


\section{References}

[1]. Hamilton JD. Oil and the macroeconomy since World War II. Journal of Political Economy 1983; 99: 228-248.

[2]. Sadorsky P. Oil price shocks and stock market activity. Energy Economics 1999; 21: 449469.

[3]. Sadorsky P. The empirical relationship between energy futures prices and exchange rates. Energy Economics 2000; 22: 253-266.

[4]. Sadorsky P.The macroeconomic determinants of technology stock price volatility. Review of Financial Economics 2003; 12: 191-205.

[5]. Papapetrou E. Oil price shocks, stock market, economic activity and employment in Greece. Energy Economics 2001; 23: 511-532.

[6]. Shahbaz M, Ahmad N, Aamir N. Stock market development and economic growth: ARDL causality in Pakistan. International Research Journal of Finance and Economics 2008; 14: 182-195.

[7]. Bénassy-Quéré A, Mignon V, Penot A. China and the relationship between the oil prices and the dollar. Technical report, 2005; CEPII.

[8]. Chen SS, Chen HC. Oil price and real exchange rates. Energy Economics 2007; 29: 390-404.

[9]. Huang Y, Guo F. The role of oil price shocks on China's real exchange rate. China Economic Review 2007; 18: 403-413.

[10]. Olomola PA, Adejumo AV. Oil price shocks and macroeconomic activities in Nigeria. International Research Journal of Finance and Economics 2006; 3: 28-34.

[11]. Kutan AM, Wyzan ML. Explaining the real exchange rate in Kazakhstan, 1996-2003: is Kazakhstan vulnerable to the Dutch disease? Economic Systems 2005; 29: 242-255.

[12]. Shahbaz M. On nominal and real devaluations relation: econometric evidence for Pakistan. International Journal of Applied Econometrics and Quantitative Studies 2009; 9: 85-108.

[13]. Shahbaz M, Ahmad N, Wahid ANM. Savings-investment correlation and capital outflow: the case of Pakistan. Transition Studies Review 2010; 17: 80-97.

[14]. Shahbaz M, Rahamam MM. Foreign capital inflows-growth nexus and role of domestic financial sector: an ARDL cointegration approach for Pakistan. Journal of Economic Research 2010; 15: 207-231. 
[15]. Shahbaz M, Awan MU, Ahmad K. The exchange value of the Pakistan rupee \& Pakistan trade balance: an ARDL bounds testing approach. The Journal of Developing Areas 2011a; 44: 69-93.

[16]. Shahbaz M, Islam F, Aamir N. Is devaluation contractionary? empirical evidence for Pakistan. Economic Change and Restructuring 2012b; 45: 299-316.

[17]. Shahbaz M, Jalil A, Islam F. Real exchange rate changes and the trade balance: the evidence from Pakistan. The International Trade Journal 2012a; 26:139-153.

[18]. Shahbaz M, Rahman MM. The dynamics of financial development, imports, foreign direct investment and economic growth: cointegration and causality analysis in Pakistan. Global Business Review 2012; 13: 201-219.

[19]. Shahbaz M. (2012). Does trade openness affect long run growth? cointegration, causality and forecast error variance decomposition tests for Pakistan. Economic Modelling 29, 23252339.

[20]. Nasreen S. Export-growth linkages in selected Asian developing countries: evidence from panel data analysis. Asian Journal of Empirical Research 2011; 1: 1-13.

[21]. Khattak NUR, Tariq M, Khan J. Factors affecting the nominal exchange rate of Pakistan: An econometric investigation (1982-2008). Asian Economic and Financial Review 2012; 2: 421-428.

[21]. Granger CW J. Investigating causal relations by econometric models and cross-spectral methods. Econometrica 1969; 37: 424-438.

[22]. Granger CWJ, Lin J. Causality in the long run. Econometric Theory 1995; 11: 530-536.

[23]. Krugman P. (1983). Oil shocks and exchange rate dynamics, in Frankel, J.A. (ed), Exchange rates and international macroeconomics, University of Chicago Press.

[24]. Golub S. Oil prices and exchange rates. The Economic Journal 1983; 93: 576-593.

[25]. Corden WM. Booming sector and Dutch disease economics: Survey and consolidation. Oxford Economic Papers 1984; 36: 359-380.

[26]. Rogoff K. The purchasing power parity puzzle. Journal of Economic Literature 1996; 34 : 647-668.

[27]. Amano RA, van Norden S. Exchange rates and oil prices. Review of International Economics 1998; 6: 683-694. 
[28]. Chaudhuri K, Daniel BC. Long-run equilibrium real exchange rates and oil prices. Economics Letters 1998; 58: 231-238.

[29]. Engle RF, Granger CWJ. Co-integration and error correction: representation, estimation, and testing. Econometrica 1987; 55: 251-276.

[30]. Rautava J. The role of oil prices and the exchange rate in Russian's economy. Bank of Finland, Institute for Economies in Transition, BOFIT Discussion papers 3/2002.

[31]. Rautava J. The role of oil prices and the exchange rate in Russian's economy-cointegration approach. Journal of Comparative Economics 2004; 32: 315-327.

[32]. Hamilton JD. What is an oil shock? Journal of Econometrics 2003; 113: 363-398.

[33]. Dawson JC. The Effect of oil Prices on Exchange Rates: A Case Study of the Dominican Republic. The Park Place Economist 2006; 14: 1-9.

[34]. Issa R, Lafrance R, Murray J. The turning black tide: energy prices and the Canadian dollar. Canadian Journal of Economics 2008; 41: 737-759.

[35]. Narayan PK, Narayan S, Prasad A. Understanding the oil price-exchange rate nexus for the Fiji islands. Energy Economics 2008; 30: 2686-2696.

[36]. Coudert V, Mignon V, Penot A. Oil price and the dollar. Energy Studies Review 2007; 18 : $1-20$.

[37]. Aziz MIA. (2009). Oil price and exchange rate: a comparative study between net oil exporting and net oil importing countries. ESDS International Annual Conference, London.

[38]. Rickne J. Oil Prices and real exchange rate movements in oil-exporting countries: the role of institutions. IFN Working Paper No. 810, 2009, Uppsala University.

[39]. Huang AY, Tseng Y-H. Is crude oil price affected by the US dollar exchange rate? International Research Journal of Finance and Economics 2010; 58: 109-120.

[40]. Naccache T. Oil price cycles and wavelets. Energy Economic 2011; 33: 338-352.

[41]. Leili N. Oil prices and exchange rates: the case of OPEC. Business Intelligence Journal 2010; 3: 83-92.

[42]. Lizardo RA, Mollick AV. Oil price fluctuations and U.S. dollar exchange rates. Energy Economics 2010; 32: 399-408

[43]. Zhang Y-J, Fan Y, Tsai H-T, Wei Y-M. Spillover effect of US dollar exchange rate on oil prices. Journal of Policy Modeling 2008; 30: 973-991. 
[44]. Ghosh S. Examining crude oil price-exchange rate nexus for India during the period of extreme oil price volatility. Applied Energy 2011; 88: 1886-1889.

[45]. Al-mulali U, Sab CNBC. The impact of oil prices on the real exchange rate of the dirham: a case study of the United Arab Emirates (UAE). OPEC Economic Review2011; 384-399.

[46]. Treviño JP. Oil-price boom and real exchange rate appreciation: is there Dutch disease in the CEMAC? IMF Working Paper 11/268/2011, Washington, D.C.

[47]. Ismail K. The structural manifestation of the 'dutch disease': the case of oil exporting countries. IMF Working Paper 10/103/2009, Washington, D.C.

[48]. Kanturk A. (2011). Impact of the international oil prices on Turkish exchange rate volatility. Department of Economics, International Burch University.

[49]. Wu C-C, Chung H, Chamg Y-H. The economic value of co-movement between oil price and exchange rate using copula-based GARCH models. Energy Economics 2012; 34: 270282.

[50]. Reboredo J. Modelling oil prices and exchange rate co-movements. Journal of Policy Modelling 2012; 34: 419-440.

[51]. Basher SA, Haug AA, Sadorsky P. Oil prices, exchange rates and emerging stock markets. Energy Economics 2012; 34: 227-240.

[52]. Hussin MYM, Muhammad F, Abu MF, Razak HAA. The relationship between oil price, exchange rate and Islamic stock market in Malaysia. Research Journal of Finance and Accounting 2012; 3: 1-10.

[53]. Benhmad F. Modeling nonlinear Granger causality between the oil price and U.S. dollar: A wavelet based approach. Economic Modelling 2012; 29: 1505-1514.

[54]. Beckmann J, Czudaj R. (2012). Oil price and U.S. dollar exchange rates dynamics. University of Duisburg-Essen.

[55]. Coleman S, Cuestas JC, Mourelle E. Investigating the oil price-exchange rate nexus: evidence from Africa. Navarra Center for International Development, Working Paper No. 03/2012.

[56]. Turhan I, Hacihasanoglu E, Soytas U. Oil prices and emerging market exchange rates. Central Working Paper No: 12/01/2012, Bank of the Republic of Turkey. 
[57]. Adeniyi O, Omisakin O, Yaqub J, Oyinlola A. Oil price-exchange rate nexus in Nigeria: further evidence from an oil exporting economy. International Journal of Humanities and Social Science 2012; 2: 113-121.

[58]. Oriavwote VE, Eriemo NO. Oil prices and the real exchange rate in Nigeria. International Journal of Economics and Finance 2012; 4: 198-205.

[59]. Englama A, Omotunde DO, Ogunleye TS, Isma'il FU. Oil prices and exchange rate volatility in Nigeria: an empirical investigation. Central Bank of Nigeria: Economic and Financial Review 2010; 48: 31-48.

[60]. Hassan S, Zahid M. The real exchange rate of an oil exporting economy: empirical evidence from Nigeria. FIW Working Paper 72/2011, September.

[61]. Ozsoz E, Akinkunmi M. (2011). An evaluation of price based determinants of Nigeria's real exchange rate. http://papers.ssrn.com/sol3/papers.cfm?abstract_id=1807163

[62]. Tiwari AK, Dar AB, Bhanja N. Oil price and exchange rates: a wavelet based analysis for India. Economic Modelling 2013; 31: 414-422.

[63]. Faria JR, Mollick AV, Albuquerque PH, Leon-Ledesma MA. The effect of oil price on China's exports. China Economic Review 2009; 20: 793-805.

[64]. Gabor D. Theory of communication. Journal Institution and Electrical Engineering 1946; 93: 429-457.

[65]. Raihan S, Wen Y, Zeng B. Wavelet: a new tool for business cycle analysis. Working Paper 2005-050A, Federal Reserve Bank of St. Louis.

[66]. Aguiar-Conraria L, Soares MJ. Oil and the macroeconomy: using wavelets to analyze old issues. Empirical Economics 2011; 40: 645-655.

[67]. Aguiar-Conraria L, Azevedo N, Soares MJ. Using wavelets to decompose the timefrequency effects of monetary policy. Phyisca A 2008; 387: 2863-2878.

[68]. Hudgins L, Friehe C, Mayer M. Wavelet transforms and atmospheric turbulence. Physical Review Letters 1993; 71: 3279-3282.

[69]. Torrence C, Compo GP. A practical guide to wavelet analysis. Bulletin of the American Meteorological Society 1998; 79: 605-618.

[70]. Torrence C, Webster PJ. Interdecadal changes in the ensomonsoon system. Journal of Climate 1999; 12: 2679-2690. 
[71]. Dickey D, Fuller WA. Distribution of the estimates for autoregressive time series with unit root. Journal of the American Statistical Association 1979; 74: 427-431.

[72]. Phillips PCB, Perron P. Testing for a unit root in time series regression. Biometrika 1988; 75: 335-346.

[73]. Zivot E, Andrews D. Further evidence of great crash, the oil price shock and unit root hypothesis. Journal of Business and Economic Statistics 1992; 10: 251-270.

[74]. Lütkepohl H. Structural vector autoregressive analysis for cointegrated variables, AStA Advances in Statistical Analysis 2006; 90: 75-88.

[75]Pesaran MH, Shin Y, Smith RJ. Bounds testing approaches to the analysis of level relationships. Journal of Applied Econometrics 2001; 16: 289-326.

[76]. Narayan PK. The saving and investment nexus for China: evidence from co-integration tests. Applied Economics 2005; 37: 1979-1990. 
Figure1: Plot of the real effective rupee exchange returns and oil returns

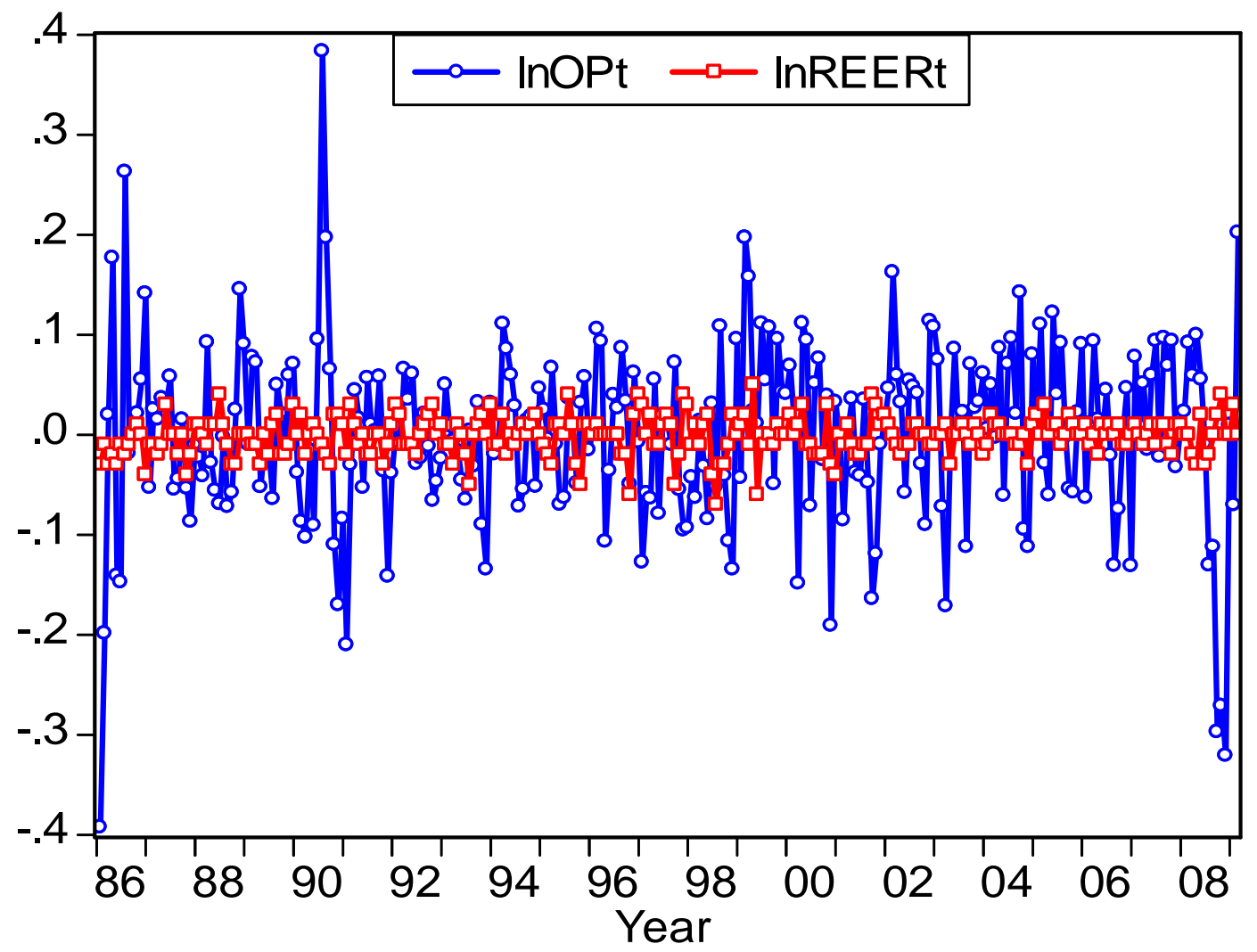


Figure-2: Continuous Wavelet Power Spectrum of $\ln R E E R_{t}$ and $\ln O P_{t}$

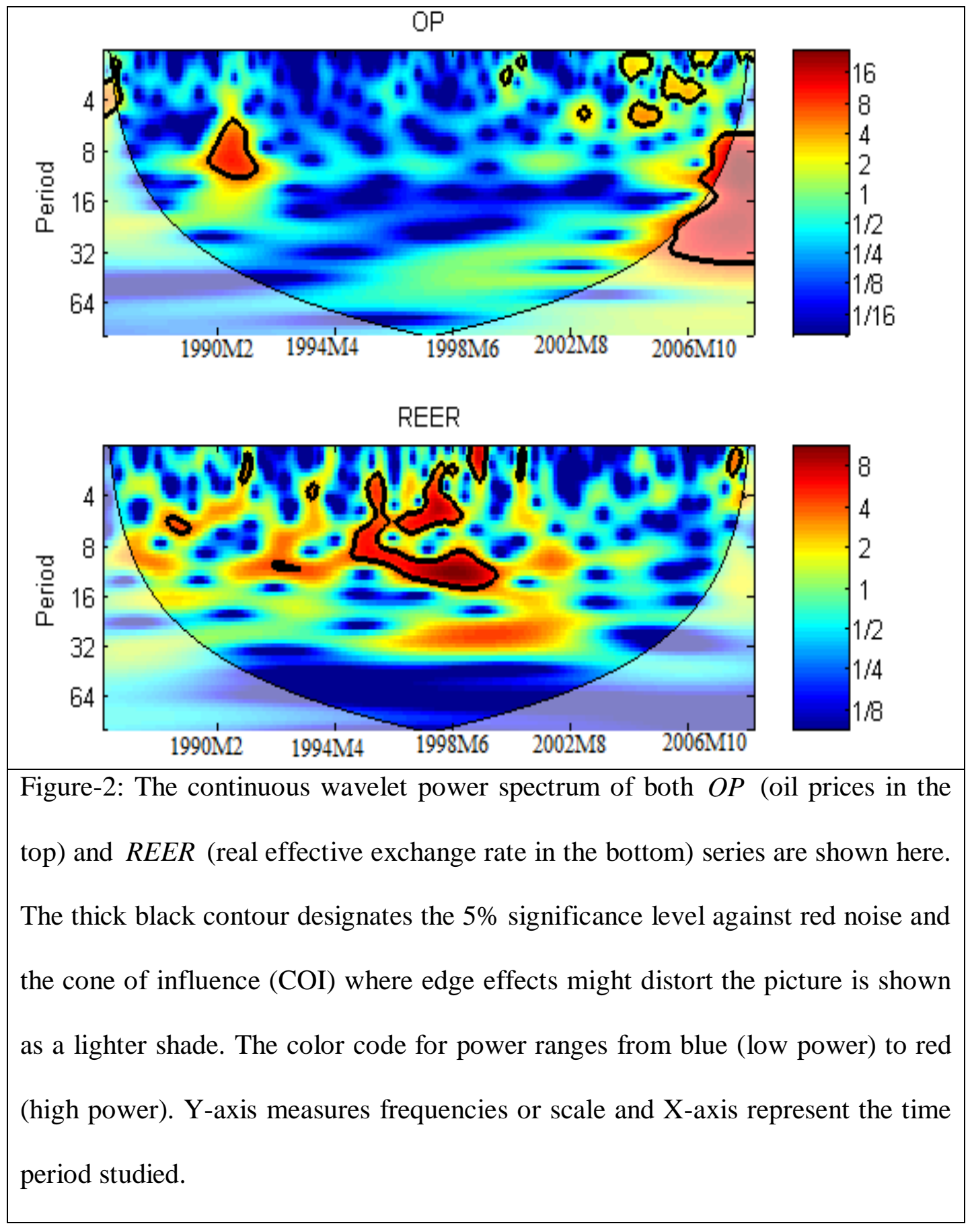


Figure-3: Cross Wavelet Transform of $\ln R E E R_{t}$ and $\ln O P_{t}$

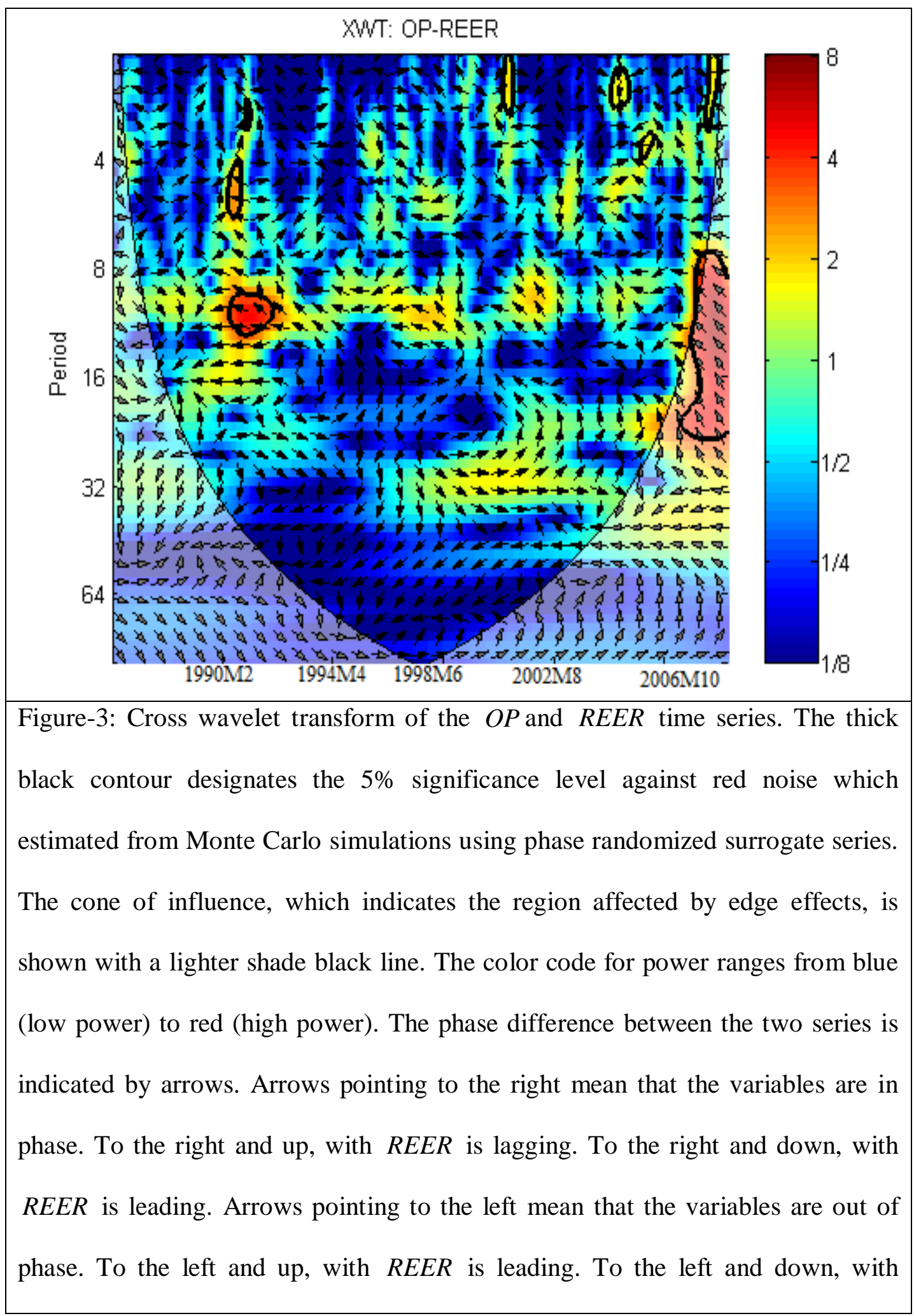


REER is lagging. In phase indicate that variables will be having cyclical effect on each other and out of phase or anti-phase shows that variable will be having antcyclical effect on each other. 
Figure-4: Cross-wavelet Coherency of $\ln R E E R_{t}$ and $\ln O P_{t}$

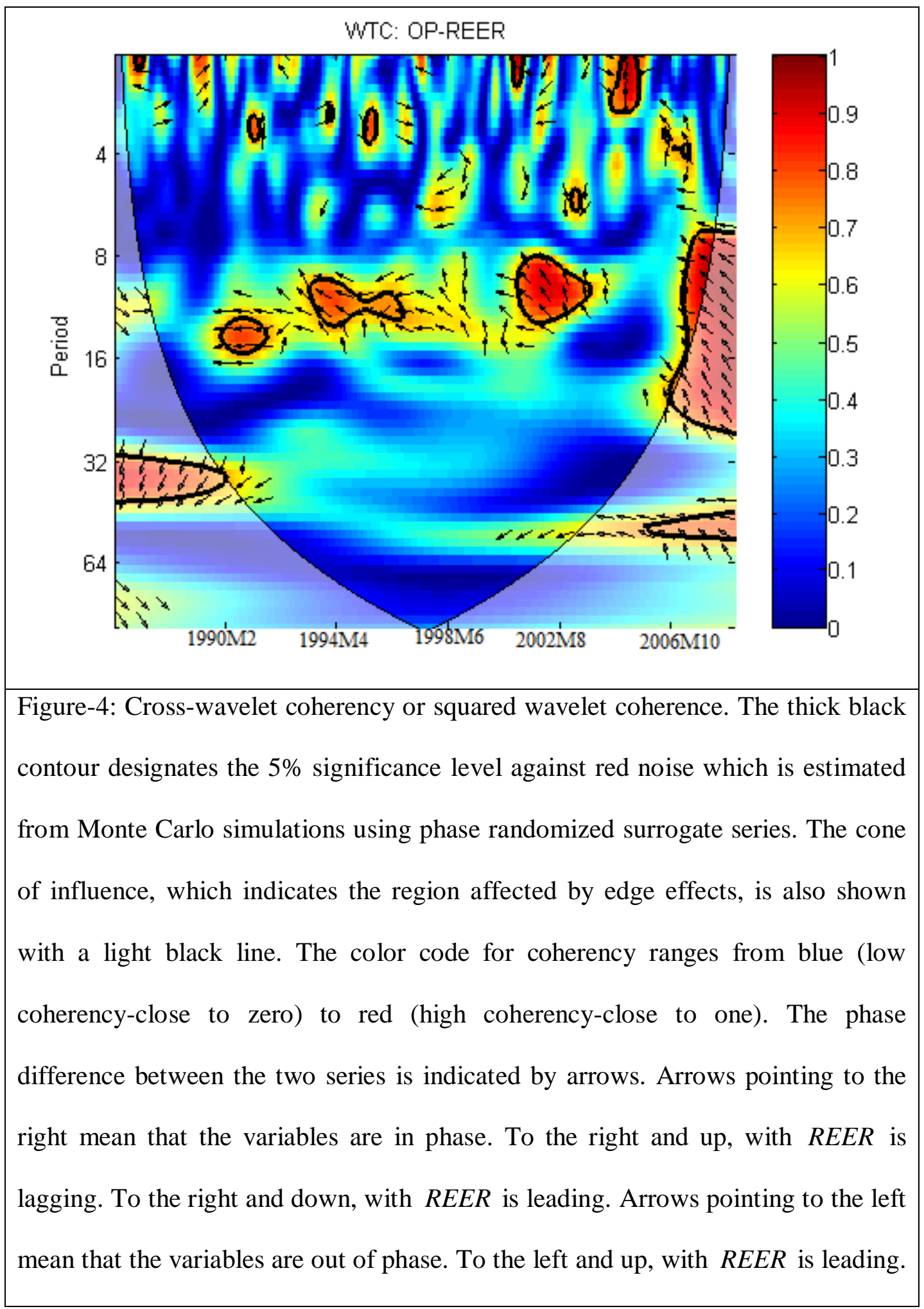


To the left and down, with REER is lagging. In phase indicate that variables will be having cyclical effect on each other and out of phase or anti-phase shows that variable will be having ant-cyclical effect on each other. 
Table-1: Descriptive Statistics of Level and Returns Series

\begin{tabular}{|l|c|c|c|c|}
\hline Variables & $\ln R E E R_{t}$ & $\ln O P_{t}$ & $\Delta \ln R E E R_{t}$ & $\Delta \ln O P_{t}$ \\
\hline Mean & 4.7407 & -1.1218 & -0.0019 & 0.0002 \\
\hline Median & 4.7500 & -1.2071 & 0.0000 & 0.0078 \\
\hline Maximum & 5.1800 & 0.1784 & 0.0500 & 0.3832 \\
\hline Minimum & 4.5300 & -2.0004 & -0.0700 & -0.3924 \\
\hline Std. Dev. & 0.1338 & 0.4076 & 0.0187 & 0.0878 \\
\hline Skewness & 0.6621 & 0.9770 & -0.3023 & -0.3849 \\
\hline Kurtosis & 3.0349 & 3.8340 & 3.8172 & 6.0161 \\
\hline $\ln R_{E E R_{t}}$ & 1.0000 & $\ldots$. & $\ldots .$. & $\ldots$ \\
\hline $\ln O P_{t}$ & -0.4045 & 1.0000 & $\ldots .$. & $\ldots$ \\
\hline$\Delta \ln R E E R_{t}$ & $\ldots .$. & $\ldots .$. & 1.0000 & $\ldots$ \\
\hline$\Delta \ln O P_{t}$ & $\ldots .$. & $\ldots .0000$ & -0.1027 & 1.000 \\
\hline
\end{tabular}


Table-2: Unit Root Analysis

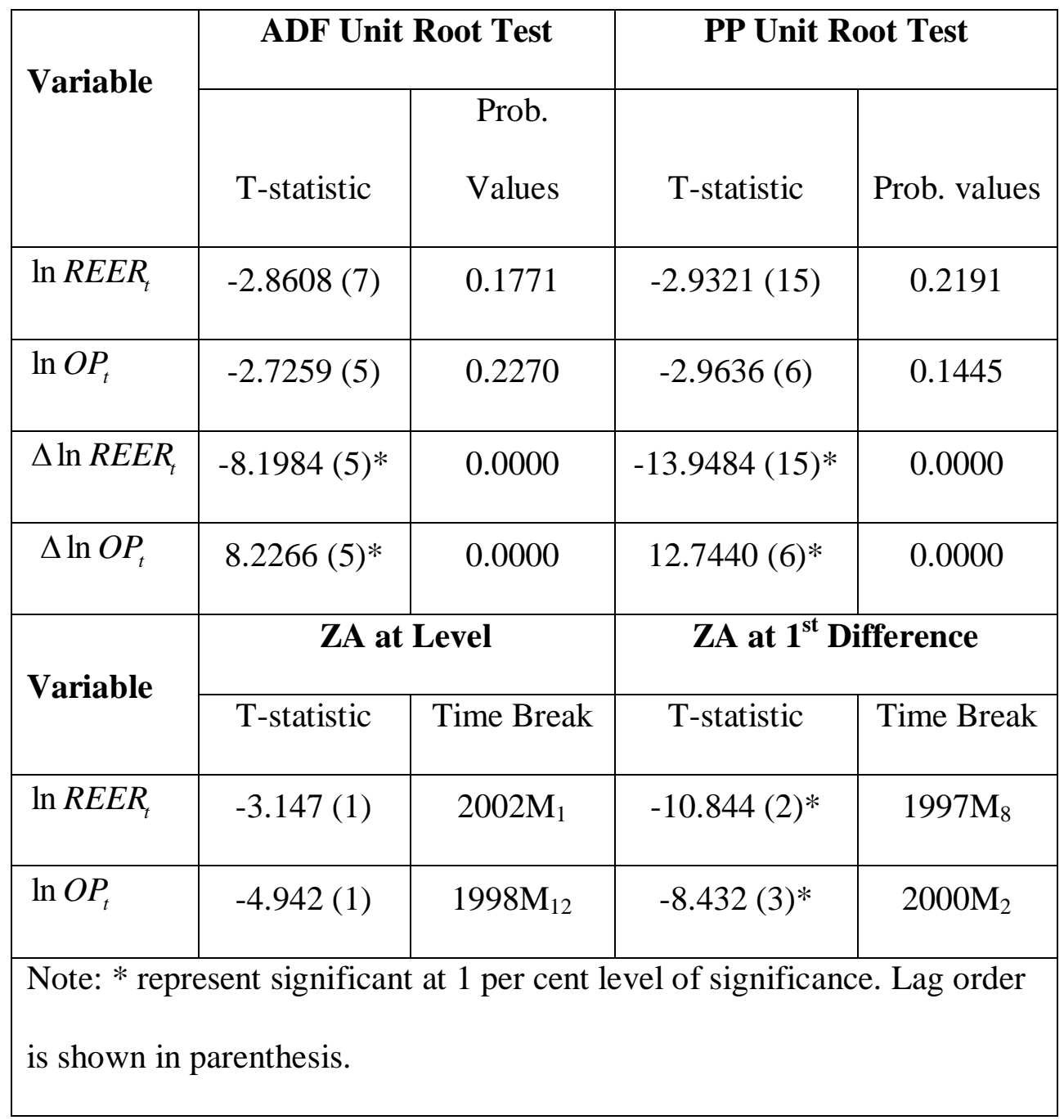


Table-3: The ARDL Bounds Testing Cointegration Analysis

\begin{tabular}{|l|l|l|}
\hline Estimated Model & $F_{\text {REER }}\left(\ln\right.$ REER $\left._{t} / \ln O P_{t}\right)$ & $F_{O P}\left(\ln O_{t} / \ln\right.$ REER $\left._{t}\right)$ \\
\hline Optimal Lag Length & $(5,3)$ & $(5,5)$ \\
\hline Structural Break & $2002 \mathrm{M}_{1}$ & $1998 \mathrm{M}_{12}$ \\
\hline F-statistics & 2.518 & $7.269^{*}$ \\
\hline Critical values & Lower Critical Bound & Upper Critical Bound \\
\hline 1 per cent level & 3.41 & 4.68 \\
\hline 5 per cent level & 2.62 & 3.79 \\
\hline 10 per cent level & 2.26 & 3.35 \\
\hline$R^{2}$ & 0.1114 & 0.2062 \\
\hline Adjusted- $R^{2}$ & $0 . .0702$ & 0.1597 \\
\hline F-statistics & $2.7065^{*}$ & $4.4354^{*}$ \\
\hline Durbin-Watson & 2.0074 & 1.9040 \\
\hline Note: * denotes the significance at 1\% level respectively. The optimal lag \\
structure is determined by AIC. Critical values bounds are from Narayan, \\
[77].
\end{tabular}




\section{MPRA \\ Munich Personal RePEc Archive}

\section{Analyzing Time-Frequency Relationship between Oil Price and Exchange Rate in Pakistan through Wavelets}

Muhammad Shahbaz and Aviral Kumar Tiwari and Mohammad Iqbal Tahir

COMSATS Institute of Information Technology, Lahore, Pakistan

23. April 2013

Online at http://mpra.ub.uni-muenchen.de/48086/

MPRA Paper No. 48086, posted 7. July 2013 09:38 UTC 
Analyzing Time-Frequency Relationship between Oil Price and Exchange Rate in Pakistan through Wavelets

\author{
Muhammad Shahbaz \\ Department of Management Sciences, \\ COMSATS Institute of Information Technology, \\ Lahore, Pakistan. Email: shahbazmohd @live.com \\ www.ciitlahore.edu.pk, UAN: 0092-42-111-001-007, \\ Fax: 0092-42-99203100, Mobile: +92334-3664-657

\section{Aviral Kumar Tiwari} \\ Faculty of Applied Economics, \\ Faculty of Management, ICFAI University, Tripura, \\ Kamalghat, Sadar, West Tripura, Pin-799210, \\ Email: aviral.eco@gmail.com

\section{Mohammad Iqbal Tahir} \\ The University of Faisalabad, Faisalabad, Pakistan \\ Griffith University, Brisbane, Australia \\ Email: advisor@tuf.edu.pk
}

